Research Article

\title{
Extent of Entry Capacity Loss at Roundabouts Caused by Rainy Conditions
}

\author{
J. Ben-Edigbe $\mathbb{C D}^{1}{ }^{1}$ A. H. Pakshir $\mathbb{D D}^{2}{ }^{2}$ and S. O. Ibijola ${ }^{1}$ \\ ${ }^{1}$ School of Engineering, University of KwaZulu-Natal, Durban, South Africa \\ ${ }^{2}$ Department of Civil Engineering, Lenjan Branch, Islamic Azad University, Isfahan, Iran \\ Correspondence should be addressed to J. Ben-Edigbe; ben-edigbe@ukzn.ac.za
}

Received 21 August 2017; Accepted 16 October 2017; Published 28 January 2018

Academic Editor: Kirk Hatfield

Copyright ( 2018 J. Ben-Edigbe et al. This is an open access article distributed under the Creative Commons Attribution License, which permits unrestricted use, distribution, and reproduction in any medium, provided the original work is properly cited.

Entry capacity loss at multilane roundabouts caused by rainfall was investigated. Traffic and rainfall data were collected continuously for eight weeks at selected sites in South Africa and Malaysia. Three classes of rainfall (light, moderate, and heavy) were used. Both linear and exponential techniques were used to model the relationship between entry and circulating traffic flows. Correction factor for entry angle and radius was introduced in the linear model equations to allow for variations in geometric data. Correction factor is not required for the exponential model technique. Notwithstanding, both techniques predicted that entry capacity loss would result from rainfalls irrespective of their intensity. Results show that light rainfall may cause about $5 \%$ entry and circulating capacity loss, moderate rainfall may cause about $12 \%$ capacity loss, and heavy rainfall may cause about $17 \%$ capacity loss. This paper proposed further studies into the effect of two circulating lanes rather than one on entry capacity at roundabouts.

\section{Introduction}

According to the HCM 2010 [1], roundabout entry capacity is "the maximum sustainable flow rate that can be achieved during a specified time period under prevailing road, traffic, and ambient conditions." Thus, suggesting that entry capacity is not a fixed number and also that rainfall can cause entry capacity loss, the extent of loss has yet to be established. In most countries including South Africa and Malaysia, the "yield-at-entry" rule in which approaching vehicles must wait for a gap in the circulating flow before entering the circle is followed. Once a gap appears in a circulating traffic stream, drivers may accept the gap, merge into the roundabout, and proceed to their exit. If there is no traffic flow in the roundabout, drivers may enter cautiously without yielding. At a multilane roundabout, drivers must yield to vehicles on both lanes. The "yield-at-entry" rule holds irrespective of prevailing road, traffic, and ambient conditions except in circumstances where the roundabout is signalized or directions are given by traffic officers. Rainfalls impair visibility of drivers and create anxiety, discomfort, and stress on roadways [2]. Since circulating traffic flow is not burdened with responsibilities of the yield rules, it begs the question, to what extent is the circulating capacity affected and how will that in turn affect the entry capacity? Will circulating and entry capacity loss be the same or different? It may be queried. Rainfall intensity is classified in many studies as light, moderate, heavy, or very heavy. Precipitation less than $2.5 \mathrm{~mm}$ per hour is classified as light, between $2.5 \mathrm{~mm}$ and $10 \mathrm{~mm}$ per hour is classified as moderate, and between $10 \mathrm{~mm}$ and $50 \mathrm{~mm}$ per hour is classified as heavy rainfall. Rainfall intensity greater than $50 \mathrm{~mm}$ per hour is classified as very heavy and violent, hence omitted in the study.

\section{Literature Review}

Roundabout is an intersection where vehicles enter through an approach road, travel in the same direction around a central reserve, and exit into their desired directions (Figure 1). When traffic volume is high, entering vehicles tend to lock up because of the yield rule. There are three types of roundabouts: mini, single, and multilane. Multilane roundabouts are governed by small diameters and deflected 


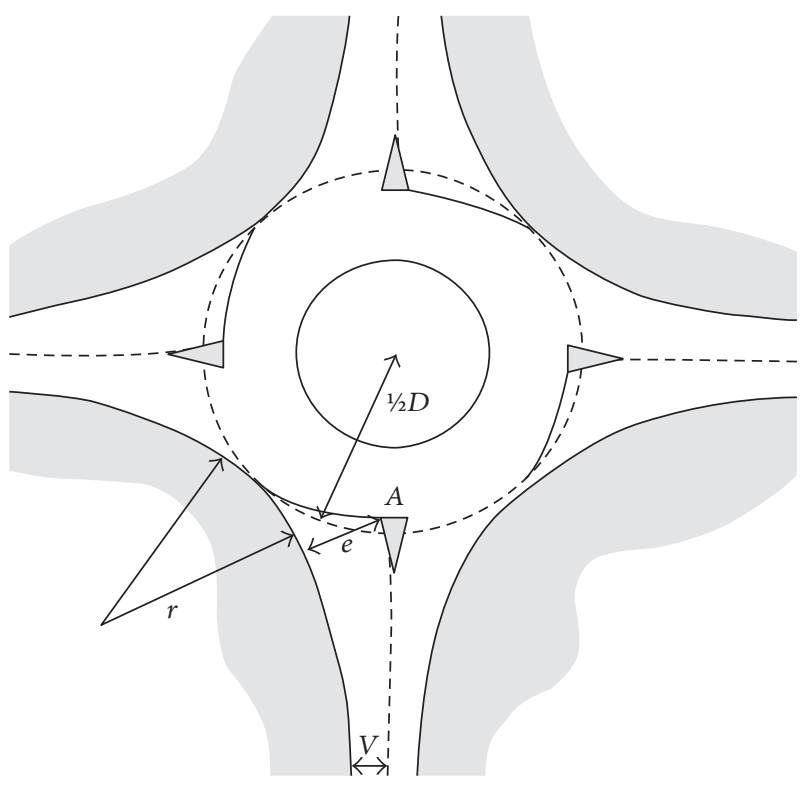

Figure 1: Geometric design features [4].

entrances [3]. Adequate deflection of the vehicle entering a roundabout is an important safety factor as it prevents vehicles from making a U-turn at entrance. Roundabouts are designed to accommodate vehicles of all sizes. The geometric elements that influence traffic flows at roundabouts include entry width, entry angle, entry radius, approach half width, inscribed circle, and the circulatory roadway width. Note that in Figure 1, "A" denotes point of maximum entry deflection at the right-hand end of the give-way line, " $e$ " denotes the entry width, " $v$ " is the approach half width, " $r$ " is the entry radius, and " $D$ " denotes the inscribed circle diameter [4]. Roundabouts require entering motorists to deflect into circular motion parallel to through traffic. By deflecting entering traffic at roundabouts, vehicles reduce their speed, which along with the presence of fewer conflict points makes the modern roundabout notably safer than a traditional signalized intersection [5].

A key assessment parameter is the entry capacity. Entry capacity is defined in the HCM 2010 as the maximum traffic flow from entry into a roundabout when the traffic flow at the entry is sufficient to cause continuous and persistent flow [1]. It can be estimated with (1) that relies on weaving, proportion of weaving vehicles, entry width, and circulating width parameters:

$$
Q_{D}=\frac{280 w\{(1+(e / w))(1-(\rho / 3))\}}{1+(w / \zeta)},
$$

where $w$ denotes the width of the weaving section, $e$ denotes the average of entry widths, $\zeta$ denotes the length of the weaving section, and $\rho$ denotes the proportion of weaving vehicles.

Entry capacity can also be estimated with (2) using a theoretical approach. The theoretical approach relies on gap acceptance. The gap-acceptance method is based on driver characteristics [6-8], that is, the estimation of individual headway parameters between entering and circulating traffic flows. The critical gap can be estimated using different methods
(Wu, Raff, and others). Wu's method is based on the equilibrium probability of the rejected and accepted headways. It does not require the predefined distribution function of the critical gaps, or assumptions about the consistency or the homogeneity of drivers. It yields the cumulative density function of the critical gaps directly [9]. According to Raff's method, the critical gap is the value of $t$ at which the functions $1-F_{r}(t)$ and $F_{a}(t)$ intercept, where $F_{a}(t)$ and $F_{r}(t)$ are accept and reject cumulative density functions, respectively [10]. The $F_{a}(t)$ curve is based on the drivers who rejected at least one lag; regarding the $F_{r}(t)$ distribution, in order to be consistent with the other methods, only the maximum rejected headway of each driver was considered. Generally, the critical gap, the follow-up time headway, and the distribution gap are the key parameters used to evaluate entry capacity. The distribution of gaps depends on the proportion of the bunched vehicle in a circulating stream. In any case, the theoretical entry capacity model equation is

$$
Q_{T}=\frac{3600(1-\varnothing) q_{c} e^{-\lambda\left(t_{c}-\tau\right)}}{1-e^{-\lambda t_{f}}},
$$

$$
\lambda=\frac{(1-\phi) q_{c}}{1-\tau q_{c}}
$$

where $Q_{T}$ is entry capacity (pcu/h), $q_{c}$ is circulating flow $(\mathrm{pcu} / \mathrm{h}), t_{c}$ is critical gap $(\mathrm{s}), t_{f}$ is follow-up headway $(\mathrm{s}), \phi$ is proportion of the bunched vehicle in a circulating stream, and $\tau$ is minimum circulating stream headway (s).

In the HCM 2010, a negative exponential regression model equation is used to model the roundabout entry capacity with inherent weaknesses, for example, choosing a negative exponential equation based on gap-acceptance theory to define the roundabout entry capacity. The equation becomes nearly asymptotic to the $x$-axis, making it unreliable to model small entry flows when circulating traffic volume is high. The absence of the $y$-intercept means that the geometric influence of a roundabout is unexplained. Notwithstanding, the HCM 2010 exponential model equation is shown below:

$$
Q_{H}=A * e^{\left(-x q_{c}\right)} \text {, }
$$

where $Q_{H}$ is entry capacity (pcu/h), $A=3600 / t_{f}$, and $\beta$ is $t_{c}-0.5 t_{f} / 3600\left(t_{f}=3.19 \mathrm{~s}\right.$ and $\left.t_{c}=4.11 \mathrm{~s}\right)$.

In passing, the HCM 2010 exponential method has not gained traction in the United Kingdom even though it has been adopted in many countries. Besides, it is easier to record direct measurement of entry and circulating flows and difficult to collect gap data at a roundabout.

Entry capacity can also be estimated with (5) and (6) using an empirical approach. The empirical approach is based on the linear relationship between entry and circulating flows. In the United Kingdom, linear regression method is preferred because it has an inbuilt substantive geometric sensitivity. The UK empirical model is based on research carried out by Kimber [11], where linear approximation was used to determine entry capacity. The key parameter in $(5)$ is the $y$-intercept $(F)$. It contains the major capacity influences of entry width, flare length, and approach width. The adjusted $y$-intercept allows the slope of the linear equation to be preserved: 


$$
Q_{E}=k(F-f c Q c) .
$$

The UK linear regression model also has a correction factor $(k)$ ability that makes it very effective for different demand flow patterns and for different geometries. As contained in previous studies [5-7, 12, 13], the entry angle and the entry radius are geometry factors that influence the entry capacity. It has been suggested by Kimber [11] that a correction factor $(k)$ shown below be added to $(7)$, where $\varphi$ is the entry angle and $r$ is the entry radius:

$$
k=1.151-0.00347 \varphi-\frac{0.978}{r} .
$$

According to Lenters and Rudy [14], geometrically sensitive design methods are often preferred by modellers to achieve required capacity targets while minimizing right-of-way impacts, avoiding high construction costs, and balancing the safety of all users. Since the paper is on impact of rainfall, then consider (5) again; when it rains, a dummy variable $(\varepsilon)$ can be introduced to depict that condition otherwise 0 for dry weather so that

$$
Q_{E}=k(F-f c Q c)+\epsilon .
$$

Capacity will shift to the left so that

$Q_{L}=\int_{0}^{R}(k(F-f c Q c)+\epsilon) d x-\int_{0}^{D}(k(F-f c Q c)+\epsilon) d x$,

where $Q_{L}$ denotes entry capacity loss.

Consider a roundabout with $n_{a}$ approaches and $n_{t}$ turning proportions. Assuming $n_{a} \times n_{t}$ matrix is the turning proportion that will contribute to the circulating traffic flow, as per Wong and Yang [15], the element of $a$ can be defined as

$$
a_{i j}= \begin{cases}1 & \begin{array}{l}
\text { if turning movement } j \text { will contribute to the } \\
\text { circulating flow across approach } i
\end{array} \\
0 & \text { otherwise }\end{cases}
$$

Now, let $b$ represent another $n_{a} \times n_{t}$ matrix entering the roundabout, element $b$.

$$
b_{i j}= \begin{cases}1 & \begin{array}{l}
\text { if turning movement } j \text { will contribute to the } \\
\text { circulating flow across approach } i
\end{array} \\
0 & \text { otherwise }\end{cases}
$$

Where the arrival rate is represented by $q_{j}$ where $j=1,2,3, \ldots, n_{t}$, the arrival rate on the approaches and circulating flows is

$$
\begin{aligned}
q_{a i} & =\sum_{j=1}^{n_{t}} b_{i j} q_{j}, \\
q_{c i} & =\sum_{j=1}^{n_{t}} a_{i j} q_{j},
\end{aligned}
$$

where $q_{a i}$ and $q_{c i}$ are the total entry and circulating flow arrival rates, respectively.

Multiply the arrival rates by a factor $u$, then the circulating flows will increase by the factor, if all approaches are

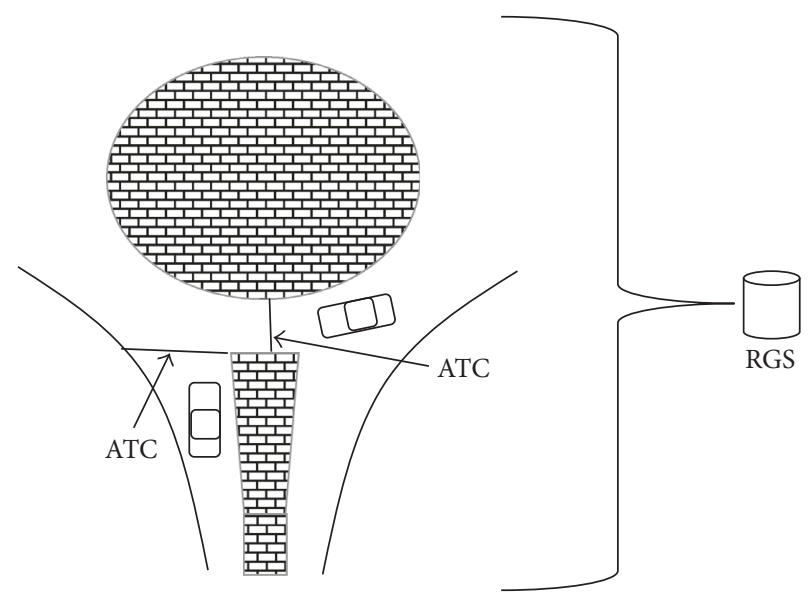

FIgURE 2: Typical setup of survey site.

undersaturated with new arrival rates. This assumption is valid because, in practice, the maximum acceptable volume/capacity ratio is less than one in other to keep the queue and delays at an acceptable level [15]. Hence, entry capacity is

$$
Q_{j}(\mu)=k_{i}\left(F_{i}-\mu f_{c i} Q_{c i}\right),
$$

where $Q_{j}$ is entry capacity (pce/hr); $Q_{c}$ is circulating flow (pce/h); $i=1,2 \cdots n_{a} ; k, F$, and $f$ are the geometric parameters; $F$ is maximum entry flow; and $f_{c}$ is gradient slope.

Wong and Yang [15] suggested that the maximum value of $\mu^{*}$ can be determined by

$$
\mu^{*}=i_{\min }\left(\frac{p_{i} k_{i} F_{i}}{\sum_{j=1}^{n_{t}} b_{i j} q_{j}+p_{i} k_{i} F_{i} \sum_{j=1}^{n_{t}} a_{i j} q_{j}}\right) .
$$

There is nothing that suggests that linear and exponential regression equations cannot be used under rainy conditions. Therefore, the paper postulates that rainfall will cause entry capacity loss, and entry capacity will shift relative to rainfall intensity irrespective of the modelling technique employed. What is not clear, however, is whether circulating traffic capacity will have an advantage over the entry capacity under rainy conditions.

\section{Data Collection}

A typical setup of survey site is illustrated in Figure 2. Note that ATC denotes automatic traffic counter and RGS denotes rain gauge station. Pneumatic tubes were installed at entry points, and traffic data were collected continuously for eight weeks per site: nearly one million vehicles at three multilane roundabouts between November 2013 and January 2014. Proximity of rain gauge is a sacrosanct requirement, and the survey site must be wholly within the catchment area of $1 \mathrm{~km}$. Three classes of vehicles, passenger cars, light vans, and bus/coach/truck, were identified, and three classes of rainfall intensity were recorded: light (intensity $<2.5 \mathrm{~mm} / \mathrm{hr})$, moderate $(2.5 \leq$ intensity $<$ $10 \mathrm{~mm} / \mathrm{hr})$, and heavy $(10 \leq$ intensity $<50 \mathrm{~mm} / \mathrm{hr})$. Although not part of the studies, poor driver visibility, changing driver behaviour, reduced speed, and general discomfort observed in passing at survey sites during rainy conditions suggest that differential traffic flow rate would result from rainfall. 
TABLE 1: Summary of geometric features.

\begin{tabular}{lcccccc}
\hline Case & $\begin{array}{c}\text { Approach } \\
\text { width }(\mathrm{m})\end{array}$ & $\begin{array}{c}\text { Entry } \\
\text { width }(\mathrm{m})\end{array}$ & $\begin{array}{c}\text { Entry } \\
\text { radius }(\mathrm{m})\end{array}$ & $\begin{array}{c}\text { Inscribed } \\
\text { diameter }(\mathrm{m})\end{array}$ & $\begin{array}{c}\text { Entry angle } \\
(\text { degree })\end{array}$ & $\begin{array}{c}\text { Estimated correction } \\
\text { factor }(k)\end{array}$ \\
\hline 1 & 7 & 10 & 20 & 50 & 45 & 95 \\
2 & 8 & 10 & 28 & 50 & 50 & 98 \\
3 & 7 & 12 & 30 & 50 & 55 & 93 \\
\hline
\end{tabular}

TABle 2: Typical entry flow (pcu/h).

\begin{tabular}{lcccc}
\hline Period & Dry & \multicolumn{3}{c}{ Rainfall } \\
\hline 1 & 828 & 521 & 712 & 629 \\
2 & 607 & 780 & 712 & 703 \\
3 & 852 & 821 & 492 & 657 \\
4 & 1053 & 667 & 501 & 734 \\
5 & 1070 & 676 & 897 & 593 \\
6 & 787 & 732 & 619 & 729 \\
7 & 796 & 664 & 679 & 813 \\
8 & 864 & 734 & 463 & 1021 \\
9 & 1048 & 842 & 741 & 744 \\
10 & 1202 & 955 & 969 & 693 \\
11 & 607 & 928 & 888 & 624 \\
12 & 979 & 1079 & 979 & 864 \\
\hline
\end{tabular}

Surveyed at-grade roundabouts have bituminous surfaces and functional and effective drainage, about one $\mathrm{km}$ from the rain gauge station. The aim of this paper is to investigate the extent of roundabout capacity loss caused by light, moderate, and heavy rainy conditions. The impact study objectives were to estimate and compare entry capacity under dry and different rainy weather conditions using both linear and exponential modelling techniques. See Table 1 for geometric design summary.

\section{Findings}

A stepwise analytical method presented in this section amplifies clarity of results, analysis, and findings.

Step 1. Determine entry and circulating traffic flows under dry weather and light, moderate, and heavy rainfalls as illustrated in Tables 2 and 3.

Step 2. Model entry and circulating traffic flows in Step 1 using both the linear and exponential regressions as shown in Figure 3 and test for statistical fitness. The coefficients of determinant $\left(R^{2}\right)$ are above 0.5 , which indicate that the model equations are reliable. The $T$-test result was greater than 2.2 at 95\% level of confidence which shows that the parameters used are significant, and the F-test result indicates that the model equations did not occur by chance. The statistical results are satisfactory. The model equations are

Exponential model: $Q_{E}=2551 e\left(-0.001 Q_{c}\right)$,

Linear model: $Q_{E}=2108-1.2344 Q_{c}$.
Table 3: Typical circulating flow (pcu/h).

\begin{tabular}{lcccc}
\hline Period & Dry & L & Rainfall & \\
\hline 1 & 1286 & 1093 & 1076 & 902 \\
2 & 1385 & 1004 & 988 & 969 \\
3 & 1382 & 1092 & 960 & 938 \\
4 & 1123 & 1006 & 960 & 954 \\
5 & 1181 & 1100 & 984 & 874 \\
6 & 1490 & 1228 & 1200 & 1120 \\
7 & 1464 & 1288 & 1101 & 1027 \\
8 & 1336 & 1262 & 1097 & 919 \\
9 & 1063 & 1001 & 1076 & 906 \\
10 & 1075 & 1099 & 912 & 956 \\
11 & 1665 & 1099 & 936 & 1004 \\
12 & 1123 & 876 & 888 & 946 \\
\hline
\end{tabular}

The estimated linear entry capacity when circulating flow is zero is $2108 \mathrm{pcu} / \mathrm{h}$, and the estimated exponential entry capacity when circulating flow is zero is $2551 \mathrm{pcu} / \mathrm{h}$. Statistical tests show that the discrepancy of $443 \mathrm{pcu} / \mathrm{h}$ is large and significant. Linear circulating flow is $1708 \mathrm{pcu} / \mathrm{h}$ when entry flow is zero, whereas the exponential curve is discontinuous at $500 \mathrm{pcu} / \mathrm{h}$, thus suggesting that small entry traffic flows are inconsequential. The exponential equation becomes nearly asymptotic to the $x$-axis making it unreliable to model small entry flows when the circulating traffic volume is high. The absence of the $y$-intercept means that the geometric influence of a roundabout is unexplained. As for the linear model equation (15), the key parameter is the $y$-intercept $(F=2108$ or $1054 \mathrm{pcu} / \mathrm{h} /$ lane). It contains the major capacity influences of entry width, flare length, and approach width. Kimber suggested that a correction factor $(k)$ be added to (15) [11]. There is no adjustment factor for the exponential function.

Step 3. Determine the geometric correction factor $(k)$ for the linear function as shown below where the entry angle is $50^{\circ}$ and entry radius is $20 \mathrm{~m}$ :

$$
k=1.151-0.00347 \varphi-\frac{0.978}{r}=0.928 .
$$

Step 4. Apply the $k$-value to the linear model equation as illustrated below:

$$
\begin{aligned}
& Q_{E}=0.928\left(2108-1.2344 Q_{c}\right), \\
& Q_{E}=1956-1.1146 Q_{c} .
\end{aligned}
$$




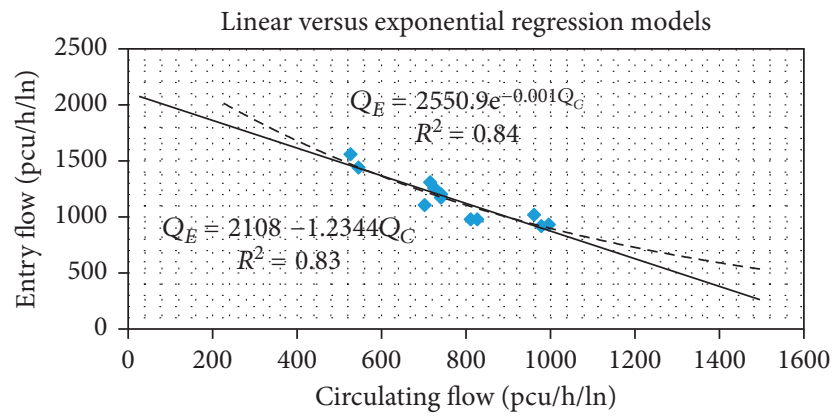

Figure 3: Typical empirical regression models.

TABLE 4: Summary of capacity shrinkage.

\begin{tabular}{|c|c|c|c|c|c|c|c|c|}
\hline \multirow{2}{*}{ Site } & \multirow{2}{*}{ Model equations } & \multicolumn{3}{|c|}{ Entry capacity $\left(Q_{E}\right)$} & \multicolumn{3}{|c|}{ Geometric parameters } & \multirow{2}{*}{ Capacity loss (\%) } \\
\hline & & Without rainfall & With rainfall & $\Delta Q_{E}$ & $k$ & Entry radius $(\mathrm{m})$ & Entry angle $\left(^{\circ}\right)$ & \\
\hline \multirow{3}{*}{01} & $Q_{E}=2280-1.17 Q_{c}-146 R_{L}$ & 2166 & 2027 & 139 & 0.95 & 20 & 45 & 6.4 \\
\hline & $Q_{E}=2211-1.09 Q_{c}-302 R_{M}$ & 2100 & 1813 & 287 & 0.95 & 20 & 45 & 13.3 \\
\hline & $Q_{E}=2159-1.04 Q_{c}-345 R_{H}$ & 2051 & 1723 & 328 & 0.95 & 20 & 45 & 16.8 \\
\hline \multirow{3}{*}{02} & $Q_{E}=1967-1.23 Q_{c}-71 R_{L}$ & 1928 & 1858 & 70 & 0.98 & 28 & 50 & 3.6 \\
\hline & $Q_{E}=1908-1.17 Q_{c}-191 R_{M}$ & 1870 & 1683 & 187 & 0.98 & 28 & 50 & 10.0 \\
\hline & $Q_{E}=1805-1.06 Q_{c}-264 R_{H}$ & 1769 & 1528 & 241 & 0.98 & 28 & 50 & 13.7 \\
\hline \multirow{3}{*}{03} & $Q_{E}=1985-0.99 Q_{c}-110 R_{L}$ & 1846 & 1744 & 102 & 0.93 & 30 & 55 & 5.6 \\
\hline & $Q_{E}=2038-1.04 Q_{c}-270 R_{M}$ & 1895 & 1644 & 251 & 0.93 & 30 & 55 & 13.2 \\
\hline & $Q_{E}=1900-0.92 Q_{c}-379 R_{H}$ & 1767 & 1414 & 353 & 0.93 & 30 & 55 & 20.8 \\
\hline
\end{tabular}

Note. $R_{L}, R_{M}$, and $R_{H}$ denote light, moderate, and heavy rainfalls, respectively.

From (17), the adjusted maximum entry capacity is $1956 \mathrm{pcu} / \mathrm{h}$ or $976 \mathrm{pcu} / \mathrm{h} / \mathrm{lane}$ and the adjusted maximum circulating capacity $\left(Q_{c}\right)$ is $1755 \mathrm{pcu} / \mathrm{h}$ or $877 \mathrm{pcu} / \mathrm{h} / \mathrm{lane}$. The exponential entry capacity of $1275 \mathrm{pcu} / \mathrm{h} / \mathrm{lane}$ is considerably higher than the adjusted linear entry capacity of $976 \mathrm{pcu} / \mathrm{h} / \mathrm{lane}$. Consequently, the exponential technique is discontinued, and the linear approach is used for the remainder of the computations.

Step 5. Compute linear functions for dry and rainy weather conditions with a dummy variable as summarized in Table 4. Test the computed model equations for statistical fitness. Estimate entry capacity for each case scenario. For example, for site 01 , the correction factor $(k)$ is 0.95 and the model equation for dry and light rainfalls is $Q_{E}=2280-1.17 Q_{c}-146 R_{L}$. The adjusted model equation is $Q_{E}=2166-1.1115 Q_{c}-139 R_{L}$. Entry capacity for dry weather when circulating traffic flow $Q_{c}$ is zer$\mathrm{o}$ is $2166 \mathrm{pcu} / \mathrm{h}$. Note that the dummy variable is zero when the weather is dry else one for rainy conditions. The entry capacity for light rainy conditions is $2166-146=2027 \mathrm{pcu} / \mathrm{h}$, and the entry capacity loss is $139 \mathrm{pcu} / \mathrm{h}(6.4 \%)$. Although not affected by the yield rule, circulating capacity also shrank. Although not affected by the yield rule, circulating capacity also shrank due to rainy conditions. For example, at site 01 , circulating capacity shrank from $1943 \mathrm{pcu} / \mathrm{h}$ to $1824 \mathrm{pcu} / \mathrm{h}$. Hence, circulating capacity loss is $1943-$ $1824=119 \mathrm{pcu} / \mathrm{h}(6.1 \%)$ less than entry capacity because of the yield rule advantage. In sum, the paper has shown that rainfall intensity can cause entry and circulating capacity loss at multilane roundabouts. Linear regression function used to compute capacity loss shows that average capacity loss for light rainfall is $5 \%$, moderate rainfall $\approx 12 \%$, and heavy rainfall $\approx 17 \%$. In all cases, capacity loss follows the same rainfall intensity pattern; therefore, it is reasonable to suggest that heavy rainfalls will have profound effect on roundabout traffic operations.

\section{Conclusions}

In this paper, linear and exponential regression functions were used in turn to model the relationship between rainy conditions and capacity loss at multilane roundabouts. Regression techniques used for the development of model functions exposed the weakness inherent in exponential curves. Based on the findings and discussions so far in this paper, it is correct to conclude that capacity loss resulting from rainfall intensity at multilane roundabouts is significant. It is also correct to conclude that capacity loss would result from rainy condition irrespective of intensity, linear relationship exists between entry capacity and circulating capacity, and that heavy rainfall is a significant contributor to capacity loss at roundabouts.

\section{Conflicts of Interest}

The authors declare that they have no conflicts of interest. 


\section{References}

[1] HCM 2010 Transportation Research Board, Highway Capacity Manual, National Research Council, Washington, DC, USA, 2010.

[2] J. Ben-Edigbe, N. Mashros, and R. Rahman, "Extent of sight distance reductions caused by rainfall on single carriageway roads," International Journal of Traffic and Transport Engineering, vol. 3, no. 3, pp. 291-301, 2013.

[3] W. Brilon and T. Miltner, "Capacity at intersections without traffic signals," Transportation Research Record: Journal of the Transportation Research Board, vol. 1920, pp. 32-40, 2005.

[4] UK Design Manual for Roads and Bridges-DMRB, vol. 6, Section 2 Part 7 TA23/81.

[5] R. A. Retting, B. N. Persaud, P. E. Gardner, and D. Lord, "Crash and injury reduction following installation of roundabouts in the United States," American Journal of Public Health, vol. 91, no. 4, pp. 628-631, 2001.

[6] R. Akçelik, E. Chung, and M. Besley, "Roundabouts: capacity and performance analysis," Research Rep. ARRB 321, Australian Road Research Board (ARRB), VIC, Australia, 1998.

[7] R. J. Troutbeck and S. Kako, "Limited priority merge at unsignalized intersections," Transportation Research Part A: Policy and Practice, vol. 33, no. 3-4, pp. 291-304, 1999.

[8] Y. H. Yap, H. M. Gibson, and B. J. Waterson, "An international review of roundabout capacity modelling," Transport Reviews, vol. 33, no. 5, pp. 593-616, 2013.

[9] N. Wu, "Equilibrium of probabilities for estimating distribution function of critical gaps at unsignalized intersections," Transportation Research Record: Journal of the Transportation Research Board, vol. 2286, no. 1, pp. 49-55, 2012.

[10] M. Raff and J. Hart, A Volume Warrant to Urban Stop Signs, Eno Foundation for Highway Traffic Control, Saugatuck, MI, USA, 1950.

[11] R. M. Kimber, “The traffic capacity of roundabouts," TRRL LR942 Monograph, 1980.

[12] O. Hagring, N. Rouphail, and H. Sørensen, "Comparison of capacity models for two-lane roundabouts," Transportation Research Record: Journal of the Transportation Research Board, vol. 2003, no. 1852, pp. 114-123, 2003.

[13] N. Kang and H. Nakamura, "Estimation of roundabout entry capacity that considers conflict with pedestrians," Transportation Research Record: Journal of the Transportation Research Board, vol. 2517, pp. 61-70, 2015.

[14] M. Lenters and C. Rudy, "HCM roundabout capacity methods and alternative capacity models," ITE Journal, vol. 80, no. 7, 2010.

[15] S. C. Wong and H. Yang, "The estimation of reserve capacity in traffic control," HKIE Transactions, vol. 4, no. 1, pp. 21-30, 1997. 


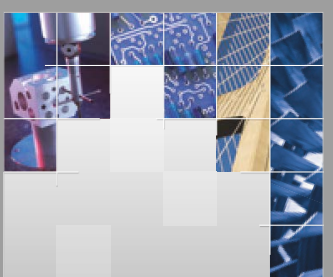

\section{Enfincering}
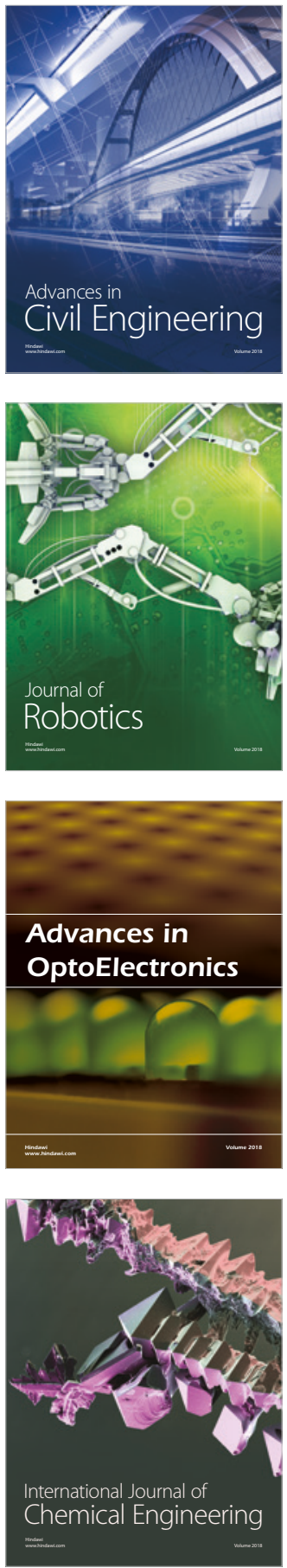

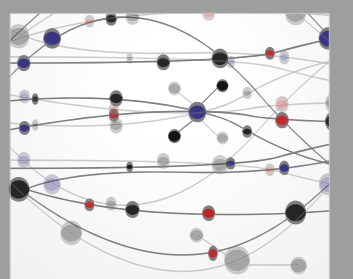

\section{Rotating \\ Machinery}

The Scientific World Journal

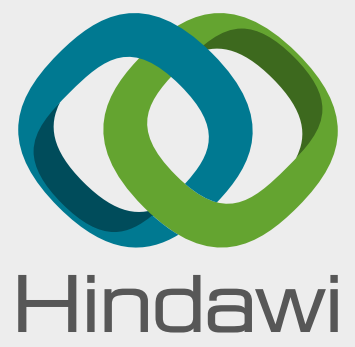

Submit your manuscripts at

www.hindawi.com
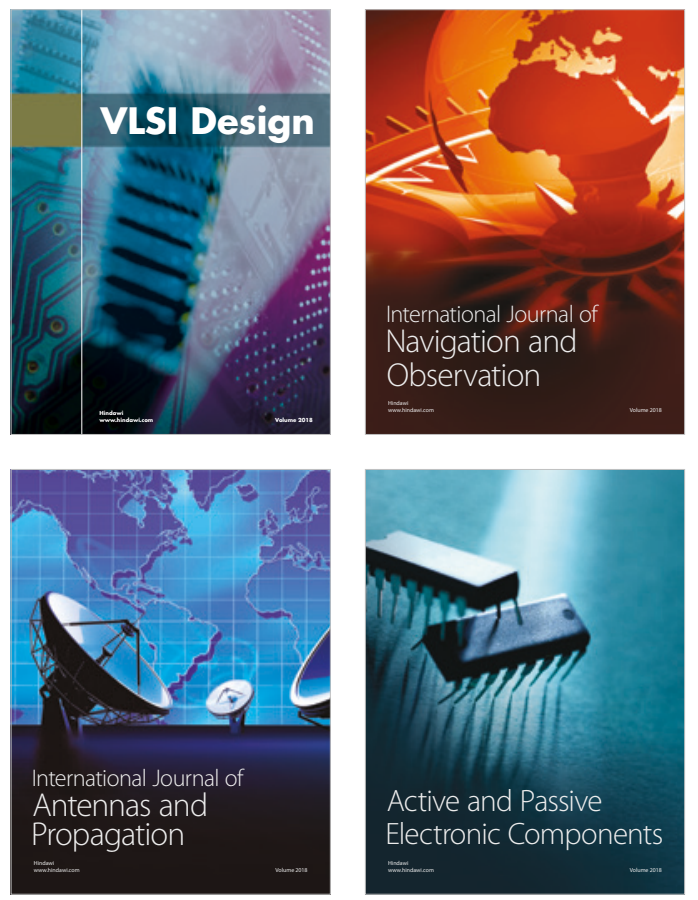
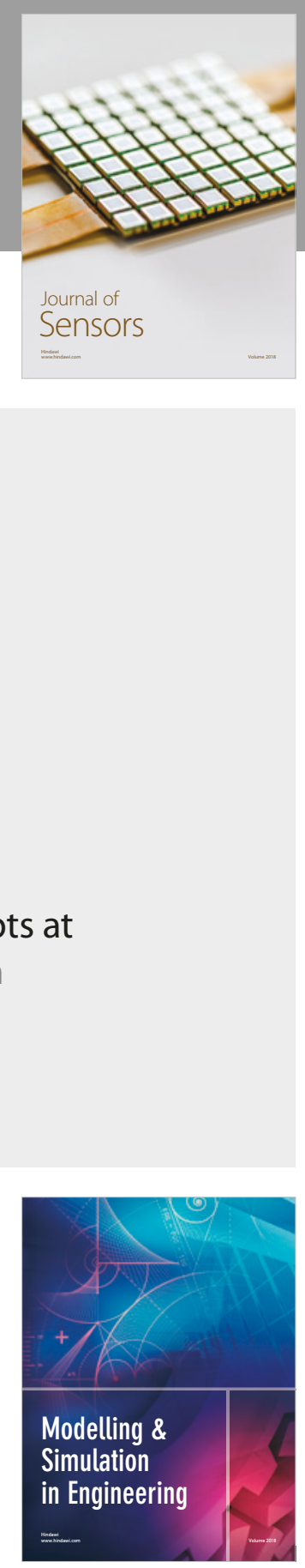

\section{Advances \\ Multimedia}
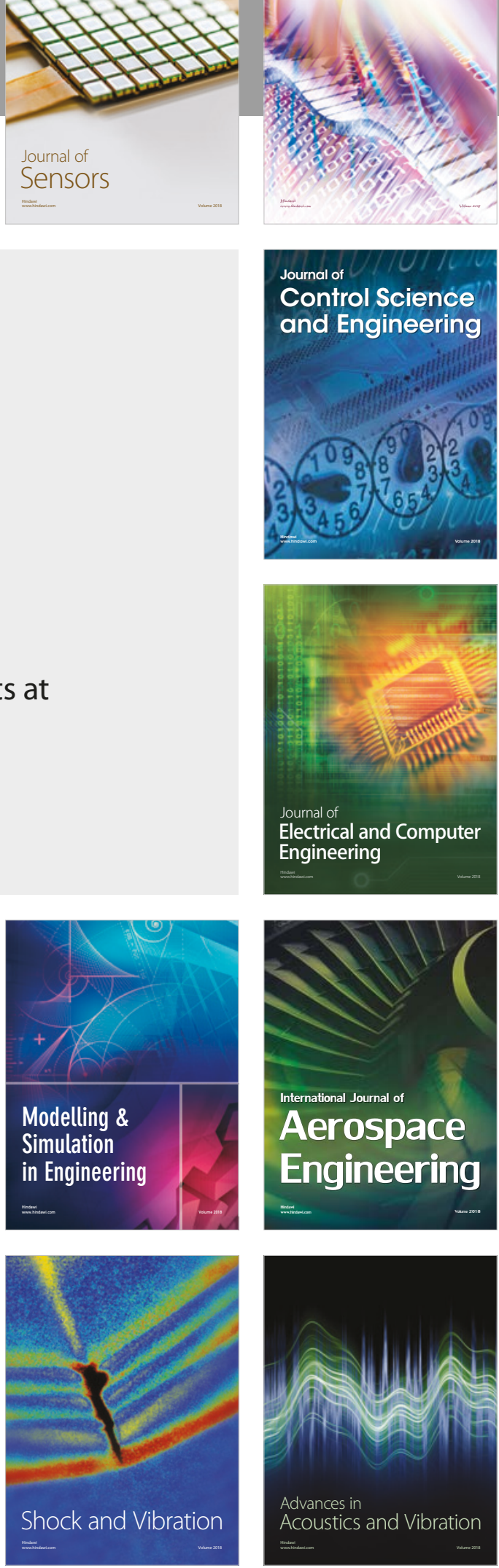